\title{
Risk Factors for Mesh Related Wound Infection after Ventral Hernia Repair Surgery
}

\author{
Nabeel J. Sagban
}

CABMS, FIBMS ,MBChB

\section{Abstract:}

Background: Mesh infection after hernia repair is a devastating complication. Preoperative prediction of high risk patients may be useful to avoid infections. This study aims at evaluating risk factors for mesh related wound infection in our setting.

Patients and methods: This prospective cohort analysis study included 120 patients underwent ventral

J Fac Med Baghdad 2015; Vol.57, No.1 Received Sept. 2014 Accepted Feb.2015 hernioplasty with polypropylene mesh from October 2009 to February 2013 at Baghdad Teaching Hospital. Clinical data analyzed to determine risk factors of mesh related wound infection.

Results: After one year follow up for each of 120; 21 patients (17.5\%) developed mesh related wound infection. Predictors of infection were: age $\geq 45$ years, $\mathrm{BMI} \geq 35 \mathrm{~kg} / \mathrm{m} 2$, diabetes mellitus, past history of previous surgical repair, presence of more than one sac or defect, defect size larger than $5 \mathrm{~cm}$, type of hernia sac content (small bowel), small bowel anastomoses, and increased duration of surgery.

Conclusion: Clinical history and examination preoperatively can predict high risk patients to develop postoperative infection.

Key word: ventral hernia, mesh, wound infection.

Introduction:

Abdominal hernia repair is one of the most common procedures in general surgery and the implementation of prosthetic meshes has substantially changed the surgical management of abdominal hernias. At first, the use of mesh prostheses was considered by the surgeons reluctantly due to the high rate of complications ${ }^{[1]}$ and, thus, reserved for specific indications. However, the development of synthetic and biologic materials and surgical training has reduced complication rates ${ }^{[2,3]}$. Mesh repairs are currently considered the standard technique for hernioplasty and have a lower recurrence rate and shorter length of stay compared to non-mesh repairs ${ }^{[4-9]}$. The increasing use of meshes in hernia repairs has introduced the potential for mesh-related complications, including seromas, adhesions, migration of the mesh, and mesh infections ${ }^{[1,3,10,11]}$. Mesh infection after hernia repair is a devastating complication. Reported incidence ranges from 0 (which has been criticized) in some series to $10.2 \%$ in others (even $38.9 \%$ in complex, contaminated hernioplasties) [3, 12, 13]. Treatment usually requires administration of systemic antibiotics and reoperation for mesh removal that may lead to hernia recurrence and the need for additional operations ${ }^{[11,14-19]}$.

\section{Patients and Methods:}

A prospective cohort analysis study including all patients admitted to; Baghdad teaching hospital $/ 3^{\text {rd }}$ surgical unit for open surgical repair of ventral hernia with polypropylene mesh (on lay technique ) during the period from October 2009 to

\footnotetext{
*Baghdad teaching hospital-Medical city.

Email:nabeelsagban@yahoo.com
}

February 2013. (a group of 120 ventral hernia patients managed with mesh repair followed up for one year

for each patient during the period of the study for mesh related wound infection) The tool for data collection was a questionnaire form for filling data about:

Personal Characteristics: Age, gender, BMI (Body mass index) and smoking.

Medical History: Diabetes mellitus, $\operatorname{COPD}($ Chronic Obstructive Pulmonary Disease), uremia, anemia, hypertension and previous cancer diagnosis.

ASA (American Society of Anesthesiologists) (Physical Status Classification System) assessment (annex- 2) ${ }^{[20]}$.

Preoperative assessment: Elective or emergency surgery, site of hernia above or below umbilicus (no umbilical hernias were found in our study) and history of previous surgical repair. Operative findings: Size of hernia defect, number of defects or sacs, sac contents, need for small bowel anastomoses, method of fixation of mesh continuous or interrupted, type of skin suture prolene or silk, method of skin closure subcuticular or mattress, and use of intraperitoneal and subcutaneous drains.

\section{Results:}

The study sample is composed of 120 patients operated for mesh repair, 21 patients (17.5\%) developed mesh related wound infection . This study found a significant association between age and infection; that infection is higher among patients aged 45 years and older $(\mathrm{P}<0.05$, table 1$)$. There was no significant association being male or female and having infection $(\mathrm{P}>$ 0.05 ,).Infection is significantly associated with body habitus of high body mass index (Obesity II or higher) $(\mathrm{P}<0.05$, table 
1). This study found there is no significant association between smoking and wound infection $(\mathrm{P}>0.05)$.

Concerning associated medical conditions;

Diabetes mellitus showed a significant association with infection $(\mathrm{P}<0.05$, table 1$)$.

COPD, uremia, anemia, hypertension, cancer and ASA score had no significant association with mesh related wound infection according to this study $(\mathrm{P}>0.05)$.

regarding preoperative surgical factors:

Elective or emergency operations had no significant association with infection $(\mathrm{P}>0.05)$.

Site of hernia above or below umbilicus had no significant association with infection ( $\mathrm{P}>0.05)$.

History of previous surgical repair is significantly associated with infection $(\mathrm{P}<0.05$, table 1$)$

Regarding operative findings:

Presence of more than one defect is also significantly associated with infection $(\mathrm{P}<0.05$, table 2$)$.It was significant to find that defect size $\geq 5 \mathrm{~cm}$. was associated with mesh infection $(\mathrm{P}<0.05$, table 2).There is a significant association between infection and type of contents of the sac that infection increases with presence of small bowel (50\%) and less with omentum (15.9\%) and preperitoneal fat $(11.1 \%)$ and less with empty sac $(0 \%)$ (P $<0.05$, table 2). There was a significant association between small bowel resection and anastomoses and infection $(\mathrm{P}<0.05$, table 2).Method of Mesh fixation(continuous or interrupted sutures) had no significant association with infection ( $\mathrm{P}>0.05$ ).Both; type of skin suture and method of skin closure had no significant association with infection $(\mathrm{P}>0.05)$.Drains; closed system (Intraperitoneal and subcutaneous) had no significant association with infection $(\mathrm{P}>0.05)$.Duration of surgery was significantly longer in infected patients than non-infected patients $(\mathrm{P}<0.05$, table 2$)$

Table 1: personal characteristics of study sample.

\begin{tabular}{ccccccc}
\hline Variables & Total & Infected & \multicolumn{3}{l}{ Not } \\
\hline N & $\mathrm{N}$ & $\%$ & $\mathrm{~N}$ & $\%$ & $\mathrm{P}$ \\
\hline Age (year);Mean \pm SD & $45.7 \pm 8.3$ & $50.7 \pm 8.8$ & $44.6 \pm 7.9$ & 0.002 \\
\hline BMI (kg/m2) ;Mean \pm SD & $32.4 \pm 2.8$ & $35.3 \pm 2.9$ & $31.8 \pm 2.3$ & $<0.001$ \\
\hline Diabetes & 30 & 10 & 33.3 & 20 & 66.7 & 0.008 \\
\hline Previous Surgical Repair & 38 & 13 & 34.2 & 25 & 65.8 & 0.001 \\
\hline
\end{tabular}

Table2:Operative characteristics of study sample.

\begin{tabular}{ccccccc}
\hline Variables & Total & \multicolumn{2}{l}{ Infected } & \multicolumn{2}{l}{ Not } \\
\hline & $\mathrm{N}$ & $\mathrm{N}$ & $\%$ & $\mathrm{~N}$ & $\%$ & $\mathrm{P}$ \\
\hline Number of Defects & & & & & & $<0.001$ \\
\hline 1 & 107 & 13 & 12.1 & 94 & 87.9 & \\
\hline$>1$ & 13 & 8 & 61.5 & 5 & 38.5 & \\
\hline $\begin{array}{c}\text { Size of Defect (cm) } \\
\text {;Mean } \pm \text { SD }\end{array}$ & $4.4 \pm 0.7$ & $5.1 \pm 1.2$ & $4.2 \pm 0.4$ & $<0.001$ \\
\hline Sac Contents & & & & & & 0.014 \\
\hline Empty & 4 & 0 & 0.0 & 4 & 100.0 & \\
\hline \begin{tabular}{c} 
Preperitoneal Fat \\
\hline Omentum
\end{tabular} & 18 & 2 & 11.1 & 16 & 88.9 & \\
\hline Bowel & 10 & 5 & 50.0 & 5 & 50.0 & \\
\hline $\begin{array}{c}\text { Bowel Anastomoses } \\
\text { Duration of Surgery } \\
\text { (minutes); } \\
\text { Mean } \pm \text { SD }\end{array}$ & $83.7 \pm 14.4$ & $97.6 \pm 17.9$ & $80.8 \pm 11.7$ & $<0.001$ \\
\hline
\end{tabular}

\section{Discussion:}

Wound infection continues to represent a major medical problem and it is of major concern when implants are used ${ }^{[21]}$. Infection rate in our study was $(17.5 \%)$ which is high in comparison to rates found in similar studies with rates varied from $4.8 \%$ to $22 \%$ by Bueno $\mathrm{LJ}$ et al ${ }^{[22]}$, Stermitzer $\mathrm{S}$ et $\mathrm{al}^{[23]}$, Swenson BR et al ${ }^{[24}$, Peterson $\mathrm{S}$ et al ${ }^{[25]}$, Buckminster Farrow et $\mathrm{al}^{[26]}$ and DimitriosXourafas et $\mathrm{al}^{27]}$.Patients aged older than 45 years are more prone to have infection, this is a fact stated in Townsend et $\mathrm{al}^{[28]}$, andF. Charles Brunicardiet $\mathrm{a}^{[29]}$ textbooks, and a finding of Stermitzer S.et $\mathrm{al}^{[23]}$,Utsumi Met $\mathrm{al}^{[30]}$, Cheadle WGet $\mathrm{al}^{[31]}$, and Mavros MN, et al ${ }^{[32]}$.Gender is not a significant association with mesh related infections; this finding goes withNorman S. Williams et $\mathrm{al}^{[33]}$ and F. Charles Brunicardiet $\mathrm{al}^{[34]}$ textbooks.It is a finding as well ofBueno LJ et al ${ }^{[22]}$ andStermitzer S.et $\mathrm{a}^{[23]}$ may be due to no physiological differences between them. Infection is significantly associated with Obesity II or higher body habitus according to this study. This is stated inBueno LJ et al ${ }^{[22]}$, Stremitzer S. et al ${ }^{[23]}$, Townsend et al ${ }^{[28]}$, Cheadle WG et al ${ }^{[31]}$, Mavros MN, et al ${ }^{[32]}$, Norman S. Williams et al ${ }^{[33]}$, F. Charles Brunicardiet al ${ }^{[34]}$ and Vivian M. Sanchez et a ${ }^{[35]}$ studies. This study found there is no significant association between smoking and mesh related wound infectionthis finding agreed withStremitzer S.et $\mathrm{al}^{[23]}$; smoking is a risk factor to this type of infection according to Townsend et al ${ }^{[28]}$, Cheadle WG et al ${ }^{[31]}$, Norman S. Williams et $\mathrm{al}^{[33]}$ and $\mathrm{F}$. Charles Brunicardiet $\mathrm{al}^{[34]}$, and this variation could be attributed to sampling error or insufficient sample size. Diabetes showed a significant association with infection this finding agreed withBueno LJ et al ${ }^{[22]}$, Townsend et al ${ }^{[28]}$, Cheadle WG et al ${ }^{[31]}$, Norman S. Williams et $\mathrm{al}^{[33]}$ andF. 
Charles Brunicardiet a ${ }^{[34]}$. While Townsend et al ${ }^{[28]}$, Norman S. Williams et al ${ }^{[33]}$, F. Charles Brunicardi et $\mathrm{al}^{[34]}$ and Vivian M. Sanchez et al ${ }^{[35]}$ state there is a significant influence of COPD, uremia, anemia, ASA score, and cancer; this study could not verify the true effect of these factors due to insufficient sample size, this is also a common finding withStermitzer S. et $\mathrm{al}^{[23]}$. Elective or emergency operations had no significant association with infection according to this study.This is in common withBueno LJ et al ${ }^{[22]}$, DimitriosXourafas et al [27] andMavros $\mathrm{MN}$, et $\mathrm{a}^{[32]}$ but differ from and Finan K.R. et $\mathrm{al}^{[38]}$ who found that emergency surgery is a significant risk factor for mesh related wound infection. Presence of previous surgical repair is significantly associated with infection; this is a finding of this study as well F. Charles Brunicardi et al ${ }^{[34]}$, Dean T. et al ${ }^{[36]}$ and Haridas M. et al ${ }^{[37]}$. Presence of more than one defect is also significantly associated with infection, this agreed withKaran Vir Singh Rana et al ${ }^{[39]}$. It was significant to find that patients with infected wound had larger defect size than non-infected patients. This is a similar finding in DimitriosXourafas et al ${ }^{[27]}$, and differs fromStremitzer S.et $\mathrm{al}^{[23]}$, andBuckminster Farrow et $\mathrm{al}^{[26]}$. Sac contents of small bowel or omentum increase the probability of mesh related wound infection, up to investigators knowledge no previous study mentioned sac contents as a risk factor for mesh related wound infection. Bowel anastomoses according to this study increase infection likelihood, this finding goes withNorman S. Williams et $\mathrm{al}^{[33]}$ andFinan K.R. et $\mathrm{al}^{[38]}$. Intraperitoneal and subcutaneous drains had no significant association with infection this differs from DimitriosXourafas et al ${ }^{[27]}$ which described themas risk factors for infection. Duration of surgery was significantly longer in infected patients this is a common finding inBueno LJ et al ${ }^{[22]}$,Stremitzer S. et al ${ }^{[23]}$, Cheadle WG et al ${ }^{[31]}$, Mavros MN, et al ${ }^{[32]} \mathrm{F}$. Charles Brunicardiet $\mathrm{al}^{[34]}$ and Vivian M. Sanchez et al ${ }^{[35]}$.

\section{Conclusions:}

The main findings of this study is that advanced age, obesity, diabetes mellitus, presence of previous surgical repair, presence of more than one defect, wider defects, and longer duration of surgery, sac contents (small bowel) and bowel anastomoses are risk factors for developing mesh infection after hernioplasty. Clinical history and examination preoperatively can predict high risk patients to develop postoperative infection.

\section{References:}

1. Mann DV, Prout J, Havranek E et al. Late onsetdeep prosthetic infection following mesh repair of inguinalhernia. Am J Surg(1998)176:12-14.

2. DeBord JR, the historical development of prosthetics inhernia surgery. SurgClin North Am (1998) 78:973-1006 VI. 3. Stephenson BMComplications of open groin herniarepairs. SurgClin North Am (2003) 83:1255-1278.
4. Rutkow IM, Demographic and socioeconomic aspects ofhernia repair in the United States in 2003. SurgClin North Am (2003) 83:1045-1051 v-VI.

5. Amato B, Moja L, Panico $S$ et al.Shouldice technique versusother open techniques for inguinal hernia repair. CochraneDatabase Syst Rev (4) (2012/Oct./7):CD001543.

6. Amid PK, Shulman AG, Lichtenstein IL Open "tensionfree" repair of inguinal hernias: the Lichtenstein technique. Eur JSurg(1996) 162:447-453.

7. Flum DR, Horvath $K$, Koepsell T. Have outcomes of incisionalhernia repair improved with time? A populationbasedanalysis. Ann Surg(2003) 237:129-135.

8. Simons MP, Aufenacker T, Bay-Nielsen $M$ et al. Europeanhernia society guidelines on the treatment of inguinal hernia inadult patients. Hernia (2009) 13:343-403.

9. EU Hernia Trialists Collaboration Repair of groin herniawith synthetic mesh: meta-analysis of randomized controlledtrials. Ann Surg(2002) 235:322-332.

10. Falagas ME, Kasiakou SK Mesh-related infections afterhernia repair surgery. ClinMicrobiol Infect (2005) 11:3-8.

11. Sanchez VM, Abi-Haidar YE, Itani KM Mesh infection inventral incisional hernia repair: incidence, contributing factors, and treatment. Surg Infect (Larchmt) (2011) 12(3):205210.

12. Chavarriaga LF, Lin E, LoskenA et al. Management ofcomplex abdominal wall defects using acellular porcine dermalcollagen. Am Surg (2010) 76:96-100.(IVSL)

13. Cobb WS, Carbonell AM, Kalbaugh CL, et al.Infection risk of open placement of intraperitoneal compositemesh. Am Surg(2009) 75:762-767 discussions 767-768.

14. Fawole AS, Chaparala RP, Ambrose NS Fate of theinguinal hernia following removal of infected prosthetic mesh.Hernia (2006) 10:58-61.

15. Luijendijk $R W$, Hop WC, van den Tol MP et al $A$ comparisonof suture repair with mesh repair for incisional hernia.N Engl J Med (2000) 343:392-398.

16. Slim K, Pezet D, Le Roux S, Chipponi J. Mesh infectionafter laparoscopic herniorrhaphy. Eur J Surg(1996) 162:247-248.

17. Szczerba SR, Dumanian GA. Definitive surgical treatmentof infected or exposed ventral hernia mesh. Ann Surg(2003) 237:437-441.

18. Taylor SG, O’Dwyer PJ. Chronic groin sepsis followingtension-free inguinal hernioplasty. Br J Surg(1999) 86:562-565.

19. Van der Linden FT, van Vroonhoven TJ Long-term resultsafter surgical correction of incisional hernia. Neth $J$ Surg(1988) 40:127-129.

20. F. Charles Brunicardi, Dana K. Andersen, Timothy $R$. Billiar et al, Schwarz's Principles of Surgery,eighth edition, The McGraw-Hill Companies, 2007;46:46-6. (IVSL)

21. F. Charles Brunicardi, Dana K. Andersen, Timothy R. 
Billiar et al, Schwarz's Principles of Surgery, eighth edition, The McGraw-Hill Companies, 2007; 8.

22. BuenoLledo J, Sosa Quesada Y, Gomez IGI et al Prostheticinfection after hernioplasty. Five years' experience. Cir Esp(2009) 85:158-164.

23. Stremitzer S, Bachleitner-Hofmann T, Gradl B et al Meshgraft infection following abdominal hernia repair: risk factorevaluation and strategies of mesh graft preservation. A retrospectiveanalysis of 476 operations. World J Surg (2010) 34:1702-1709.Doi: 10.1007/s00268-010-0543-z.

24. Swenson BR, Camp TR, Mulloy DP, et al. Antimicrobialimpregnated surgical incises drapes in the prevention ofmesh infection after ventral hernia repair. Surg Infect (Larchmt) (2008) 9:23-32.

25. Petersen $S$, Henke $G$, Zimmermann L, et al. Ventral rectus fascia closure on top of meshhernia repair in the sublay technique. PlastReconstrSurg(2004) 114:1754-1760.

26. Buckminster Farrow, Samir Awad, David H. Berger et al, More than 150 consecutive open umbilical hernia repairs in a major Veterans Administration Medical Center, The American Journal of Surgery (2008) 196, 647-651.

27. DimitriosXourafas, Stuart R. Lipsitz,, Paolo Negro et al, Impact of Mesh Use on Morbidity Following Ventral Hernia Repair With a Simultaneous Bowel Resection, ARCH SURG/ VOL 1452010 (NO. 8). (IVSL)

28. Richard T. Ethridge, MD, PhD Mimi Leong, MD Linda G. Phillips, MD. Wound Healing. Townsend, Jose Acosta, Charles A. et al: Sabiston Textbook of Surgery, 18th ed., Saunders, An Imprint of Elsevier,2007; 8.

29. F. Charles Brunicardi, Dana K. Andersen, Timothy $R$. Billiar et al, Schwarz's Principles of Surgery, eighth edition, The McGraw-Hill Companies, 2007; 5:5-7.

30. Utsumi M, Shimizu J, Miyamoto A et al, Age as an independent risk factor for surgical site infections in a large gastrointestinal surgery cohort in Japan, J Hosp Infect. 2010 Jul; 75(3):183-7. doi:10.1016/j.jhin.2010.01.021. (IVSL)

31. Cheadle WG., Risk factors for surgical site infection,Surg Infect (Larchmt). 2006; 7Suppl 1:S7-11.

32. Mavros MN, Athanasiou S, Alexiou VG et al, Risk factors for mesh-related infections after hernia repair surgery: a metaanalysis of cohort studies., World J Surg. 2011 ;35(11):238998. doi: 10.1007/s00268-011-1266-5.

33. David J. Leaper. Surgical infection. Norman S. Williams, Christopher J.K. Bulstrode, P. RONAN O'CONNELL et al, Bailey \& Love's SHORT PRACTICE of SURGERY $25^{\text {th }}$ edition, Edward Arnold (2008), 4:4.4.

34.F. Charles Brunicardi, Dana K. Andersen, Timothy R. Billiar et al, Schwarz's Principles of Surgery, eighth edition, The McGraw-Hill Companies, 2007; 5:5-7.

35. Vivian M. Sanchez, Youmna E. Abi-Haidar, and Kamal M.F. Itani. Mesh Infection in Ventral Incisional Hernia Repair: Incidence, Contributing Factors, and Treatment.
Surgical Infections. June 2011, 12(3): 205-210. doi:10.1089/ sur.2011.033. (IVSL)

36. Dean T. and contributors, VENTRAL HERNIA REPAIR COMPLICATIONS, Dec 20, 2009.

37. Haridas M. et al, Predictive factors for SSI in general surgery (retrospective study 10.253 operations), 2008. (IVSL) 38. Finan KR, Vick CC, Kiefe CI, et al, Predictive factors of wound infection in ventral hernia repair(retrospective, multicenter study in 1505 operations), Am J Surg. 2005 Nov; 190(5):676-81.

39. Karan Vir Singh Rana, Gurjit Singh, Niteen A Deshpande et al, Postoperative complications of mesh hernioplasty for incisional hernia repair and factors affecting the occurrence of complications, Medical Journal of Dr.D.Y.Patil University, India 2013 | Volume: 6 | Issue: 1 | Page: 25-31. 